\title{
Family Background and Educational Attainment - Are there Birth Order Effects in Germany?
}

\author{
Martina Eschelbach* \\ Deutsche Bundesbank and University of Erlangen-Nuremberg
}

JEL 121; J13

Birth order; sibling configuration; educational attainment; Germany; gender differences.

Received: 22.07.2013

Revision received: 18.12 .2013

Accepted: 07.03.2014

\section{Summary}

This paper contributes to the literature on the determinants of children's human capital by analyzing the effects of birth order in Germany. These effects are typically attributed to sibling rivalry for parental resources. For our analysis we use data collected as part of the German Life History Study on birth cohorts 1946-1977. We find a substantial positive impact of being first born on the probability of completing higher secondary education. Analyzing gender differences, we find stronger effects for boys. Furthermore, birth order effects are more prevailing in small families. The results are discussed against the background of equal opportunities in the German educational system.

\section{Introduction}

In many western societies, there is a discussion to what extent the educational system in place can guarantee equal opportunities. Ideally, educational success should be independent of factors that an individual cannot influence. In Germany a major concern for policy-makers is that educational attainment still heavily depends on family background. Parental education, income and wealth are still decisive factors to explain why some children attain higher secondary education and other children do not (Wössmann 2004; Heineck/Riphahn 2009). In Germany as in many other western countries "the accident of birth" into a certain family environment is a major source of inequality Heckman (2008). In this paper we want to broaden the debate on the importance of family background for educational attainment in Germany. In contrast to the studies cited above, we are looking for systematic inequalities within families rather than across. A family constitutes a socio-economic subsystem where economic allocation decisions are made and social relationships are established (Becker 1981; Becker 1996). These intra-family processes can lead to systematic inequalities between siblings from the same family. One important

\footnotetext{
* The author would like to thank Regina T. Riphahn, Miriam Mäder, Barbara Hanel, Christoph Wunder and Robert Orlowski as well as two unknown referees for their helpful comments on earlier versions of this paper. This article represents the author's personal opinion and does not necessarily reflect the views of the Deutsche Bundesbank or its staff.
} 
factor that determines a child's relative position in a family is birth order. Different birth ranks can engender different parental treatment and a different standing in the sibling row, which later may translate into differential schooling success. In this context, "the accident of birth order" could be a source of inequality. In this paper we study whether in Germany the coincidence of being first born or not has implications for the level of secondary education a child is able to achieve later in life.

The question whether there are systematic intra-family differences depending on birth order has interesting implications for the research on equal opportunities. Taking into account birth order effects is important in order to correctly determine the total impact of family background on educational success and, in a second step, life-time earnings. There is a large body of literature which quantifies this impact by the estimation of sibling correlations (e.g. Hauser/Wong 1989; Solon et al. 1991; Sieben et al. 2001; Conley/Glauber 2008; Mazumder 2008; Björklund et al. 2010; Schnitzlein 2014). The idea behind this approach is that if siblings from the same family show a strong resemblance in educational attainment or earnings the impact of family background can be considered as high. Neglecting the effects of birth order in such a comparison could, however, bias the estimates of the total impact of family background on educational success downwards. Siblings from the same family necessarily have different birth ranks. If different birth ranks imply different educational opportunities, not conditioning on birth order would underestimate the true resemblance of siblings and thus the global impact of family background.

The influence of birth order on educational attainment has recently been established for Norway (Black et al. 2005), the U.S. (Kanterevic/Mechoulan 2006; de Haan 2010), and the UK (Booth/Kee 2009). The studies agree on disadvantages for later born children compared to the oldest sibling in a family. Based on Norwegian administrative data, Black et al. (2005) find that second born children have on average 0.3 fewer years of schooling than first born children. For children born tenth or later the disadvantage even amounts to one year. Booth and Kee (2009) find similar effects for families in the British Household Panel Survey. De Haan (2010) uses data from the Wisconsin Longitudinal Study. She finds that in U.S. families, being one rank higher in the sibling row reduces years of schooling on average by around 0.3 .

This paper provides empirical evidence on the relationship between birth order and educational attainment in Germany. Guided by earlier empirical research (Black et al. 2005; Kantarevic/Mechoulan 2006; Booth/Kee 2009; de Haan 2010) we address the following questions: do later born children have a disadvantage over their older siblings in terms of educational attainment? Do these birth order effects differ between boys and girls? Do the effects depend on family structure? ${ }^{1}$

We use data from the German Life History Study and exploit information on West German siblings born between 1946 and 1977. We are interested in the effects of birth order on secondary education. Using a family fixed effects model, we are able to control for family-level heterogeneity. Our findings for Germany are largely consistent with those from other countries: we find highly significant negative effects of higher birth order. The effects are systematically stronger for boys and depend on family size.

1 For an analysis of trends in birth order effects and differences between West Germany and formerly socialist East Germany see Eschelbach (2009). 


\section{Theoretical concepts regarding the connection between birth order and educational attainment}

When discussing the effects of birth order on children's educational attainment, we must bear in mind that family research is multi-disciplinary. The theoretical framework presented in this section therefore comprises complementary explanatory approaches from economics, sociology, and psychology. Most theories explain birth order effects by a "non-shared family environment" (Sulloway 2007a) during childhood: depending on their birth rank, children experience a different parental treatment (2.1) and have different relations with their siblings (2.2). A third approach explains birth order effects by parents' fertility decision (2.3).

\subsection{The parental allocation problem}

Human capital theory (e.g. Becker 1981) considers a child's schooling achievements as the outcome of a child production function for which parental resources are the crucial input. If there are several children in a family, parents must divide their resources such as money, quality time, attention, and energy among the children. Sibling outcomes may differ if parents' allocation strategy results in an unequal distribution (Behrman/Taubman 1986). One possible strategy to assign resources is to favor certain children depending on certain child characteristics, e.g. birth order. Becker and Tomes (1976) argue that rational parents aim to maximize their children's future wealth. They invest more in the human capital of capable children because of higher returns. Parents often perceive their oldest child as the most capable. Because of the age gap, it always appears physically stronger, more skillful and intelligent in direct comparison to its younger siblings. And indeed, in many human societies, there is historical evidence of parental favoritism towards the first born child, for example in terms of lines of succession and family customs (Sulloway 2007b). Investing in the most profitable child is the optimal strategy from an economic point of view and might be appropriate when resources are extremely scarce. Hertwig et al. (2002), however, argue that in reality, parents are simply not able to follow this strategy because they fail to assess the future returns on their investments. Therefore, parents use much simpler allocation strategies such as equal treatment. Strictly speaking, total equality would mean that the cumulative distribution of resources over time is equal for every child. That is, every child gets exactly the same amount of parental resources during childhood. In that case, we would expect no birth order pattern in educational attainment. As this approach is almost impossible to accomplish, parents might draw on a more feasible equity heuristic: they attempt to treat their children equally at every point in time (Hertwig et al. 2002; Price 2008). However, Hertwig et al. (2002) demonstrate how this egalitarian behavior produces inequality among siblings: the first born is an only child for some time whereas the later born have to share parental resources from the beginning with their older siblings. ${ }^{2}$ One would expect this allocation strategy to be most harmful

\footnotetext{
2 The disadvantage for the later born only occurs, if the total amount of resources parents are willing and able to supply to their children is constant over siblings, or if at least it is not rising proportionally to the number of children. The latter assumption can be justified by a parental budget constraint (time, money etc.) or by a diminishing marginal utility in parenting with every further child (Behrman/Taubman 1986). Yet, we do not only have to consider the quantity, but also the quality of parental resources. There might be learning effects in parenting with a growing number of children. The later born children then also have an advantage as they are brought up by more experienced parents.
} 
for the middle born children and less for the last born child as the last born child will de facto become an only child once its older siblings have grown up. Such reasoning assumes, however, that the last child can equalize the lack of resources in the critical development years at a later age, which is not necessarily the case (Shonkoff/Phillips 2000).

\subsection{Sibling interaction}

Psychological and sociological theories also focus on sibling interaction. Sulloway (1996) argues that the personality and the future social behavior of a child are largely shaped by its birth order. As siblings have to share their parents' resources, rivalry emerges. The strategy a child adopts to gain parents' devotion differs by birth order. Firstborns are observed to gain their parents' favor by acting as a surrogate parent for their younger brothers and sisters. They are therefore supposed to be more conscientious, hard-working, and respectful of authority. The later born must find another niche to attract their parents' attention. As they do this by experimentation, they are often more ingenious, unconventional, and tolerant of risk (e.g., Paulhus et al. 1999; Sulloway 2001; Herrera et al. 2003; Healey/Ellis 2007).

Similarly, birth order is decisive for the strategy siblings adopt in relation to one another. Different birth ranks imply differences in age, height, and physical strength, and thus a different standing in the sibling hierarchy. Accordingly, firstborns mainly employ dominating strategies (e.g. intimidation and physical aggression) whereas high birth order siblings use low power strategies (e.g. appealing to parents for help, humor, and social intelligence) (e.g., Paulhus et al. 1999; Sulloway 2001). The different strategies later translate into differences in personality and social behavior.

In this framework, the observed correlation between birth order and schooling success can be explained by different characters of the siblings: children born early in the sibling row are doing better at school because they have certain characteristics that are helpful in the educational system. The power of personal traits in explaining socio-economic outcomes has also been confirmed in the economic literature (Heckman et al. 2006; Borghans et al. 2008).

Naturally, the life of siblings consists not only of rivalry. There are other forms of interaction such as learning and teaching relationships with the younger children learning from the older ones. In this context, Zajonc (1976) developed the much cited "confluence model”. According to Zajonc (1976), the intellectual development of a child is determined by the intellectual environment in the family which is modeled as the average of the intellectual level of all family members. With every additional child, the average intellectual environment in the family declines. The first born has the advantage of being an only child for the first few years and profits from the intellectually sophisticated environment in the sole presence of the parents. The following children are born into a successively degrading intellectual environment. Therefore, we would expect a negative effect of birth order on the intellectual development and educational success of the siblings.

Additionally, Zajonc and Markus (1979) stress the importance of the teaching function of older siblings. At first sight, this seems to benefit the younger siblings who learn from their older brothers and sisters. In the long run, however, Zajonc and Markus (1979) argue that teaching benefits the tutor more than the learner. First born children exceed later born children in terms of cognitive abilities at later age. Last born children completely lack the opportunity to teach younger siblings which creates a handicap for their intellectual development. 


\subsection{Optimal stopping theory}

According to the theories outlined so far, birth order affects child quality through childhood experience. The optimal stopping approach broadens the perspective and takes into account parents' fertility behavior (e.g. Black et al. 2005). The essential assumption is that parents base their fertility decision on their experience with previous children. On the one hand, parents with one child will only have further children, if they get along well with the first one. Thus first born children who have younger siblings are a positive selection from all children born first to their parents (including only children) and are therefore likely to perform well at school. ${ }^{3}$ On the other hand, parents who have further children will stop when they experience severe problems with their latest child. Thus, on average the last child of a family is more likely to behave and perform badly.

All of the theories presented above predict a disadvantage for later born siblings in terms of educational attainment. In the following analysis, we investigate whether this phenomenon is present in German families.

\section{Empirical approach}

\subsection{Data and sample}

We use data from the German Life History Study. ${ }^{4}$ The data consist of a series of retrospective birth cohort studies. Between 1985 and 1997, individuals born between 1919 and 1974 from both West and East Germany were interviewed about their lives with an emphasis on educational, occupational, family, and residential histories. Among other things, the respondents were asked about their parental background and their siblings. As these data contain the year of birth and the educational qualification of each brother or sister of the respondent, we are able to use the siblings of the respondents as separate observations. We now dispose of a multilevel dataset with families on the first, and siblings on the second level.

As we are interested in birth order effects in the current German educational system, we only use families from West Germany whose children were all born after 1945. Following previous research on birth order effects, we restrict the analysis to families with at least two children because in families with only one child there cannot be sibling inequalities. ${ }^{5}$ Our initial sample consists of 13,155 siblings from 4,280 families.

Similar to previous studies (e.g., Black 2005; de Haan 2010), we analyze birth order effects only in intact families. This restriction accounts for the argument that part of the expected negative birth order effect may be due to family problems (e.g. divorce or death of a parent) which a later born child is more likely to be confronted with than a first born child. To address this problem, we have to exclude a number of families. We drop a family when the respondent had a stepmother or stepfather, when the respondent was separated from one of the parents during childhood, when the parents of the respondent had never been married, or when the biological mother of the respondent was younger

3 Early childhood behavior has been shown to be a good predictor of schooling outcomes (Currie/ Stabile 2006; Fletcher/Wolfe 2008).

4 For detailed information see Brückner and Mayer (1998).

5 According to the optimal stopping theory discussed in section 2.3, dropping only children might result in a positive selection of first born children in our sample. We therefore repeated our analysis including only children. The results are highly similar to those without only children (results not presented). 
than 15 or older than 49 when she gave birth. ${ }^{6}$ After these modifications we are confident to have identified and excluded most of the broken families in our sample. The restrictions reduce our sample by around 24 percent.

As a retrospective interview-based survey, the German Life History Study suffers from missing values. When a sibling has a missing value in the dependent variable educational degree, we remove that observation from our data and lose another six percent of the observations. Furthermore, we drop siblings who were younger than 22 at the time of the interview as for these observations, secondary education might not have been complete. When information on a year of birth is missing, we delete all siblings of the family, as in this case, we are not able to determine birth ranks. This leads to a further four percent reduction in sample size. For all other covariates, we replace missing values by cohort specific means.

The final estimation sample consists of 9,453 siblings from 3,282 West German families who were born between 1946 and 1977. Figure 1 shows the distribution of birth cohorts in our sample. Individuals born in 1954, 1955, 1956, 1959, 1960, 1961, 1964 and 1971 are overrepresented. This is because the German Life History Study did not sample equally across cohorts but concentrated on individuals who were born in the aforementioned years. However, as the sample does not only include the respondents but also their siblings, it covers the entire range of birth cohorts between 1946 and 1977.

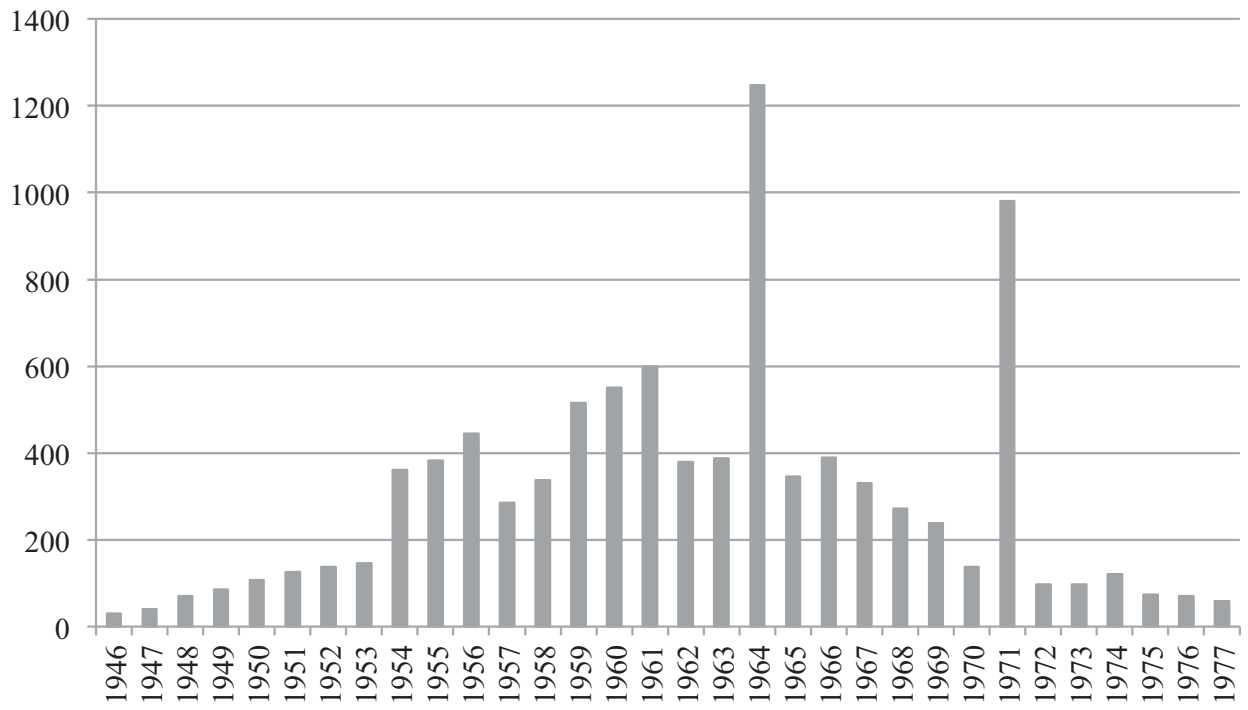

Source: German Life History Study, own calculations.

Figure 1 Distribution of birth cohorts (number of individuals)

6 These sample restrictions are entirely based on information on the interviewed sibling. As we do not have the same information for the other siblings, we cannot ensure, e.g., that all the children of a family are biological siblings. 


\subsection{Educational attainment}

Table 1 shows summary statistics of all variables used in our analysis. The outcome of interest is the completed level of secondary education. ${ }^{7}$ Previous empirical studies on birth order use years of schooling to measure educational attainment. However, this is not the best variable to model educational outcomes in a tracked educational system such as the German one. In Germany, after completing four years of primary school, pupils are separated into three different secondary school tracks: Hauptschule (lower secondary

Table 1 Summary statistics

\begin{tabular}{|c|c|c|}
\hline Variables & Mean & SD \\
\hline \multicolumn{3}{|l|}{ Secondary education } \\
\hline No secondary education & 0.03 & \\
\hline Lower secondary education & 0.40 & \\
\hline Secondary education & 0.30 & \\
\hline Higher secondary education & 0,27 & \\
\hline Birth order & 2.27 & 1.37 \\
\hline Sibship size & 3.67 & 1.73 \\
\hline Male & 0.52 & \\
\hline Maternal age at birth & 27.42 & 5.31 \\
\hline Paternal age at birth & 30.49 & 6.07 \\
\hline Year of birth & 1962.41 & 6.41 \\
\hline Working mother during childhood & 0.49 & \\
\hline \multicolumn{3}{|l|}{ Father's education } \\
\hline No secondary education & 0.06 & \\
\hline Lower secondary education & 0.70 & \\
\hline Secondary education & 0.11 & \\
\hline Higher secondary education & 0.13 & \\
\hline \multicolumn{3}{|l|}{ Mother's education } \\
\hline No secondary education & 0.08 & \\
\hline Lower secondary education & 0.73 & \\
\hline Secondary education & 0.14 & \\
\hline Higher secondary education & 0.05 & \\
\hline \multicolumn{3}{|l|}{ Father's professional education } \\
\hline No professional education & 0.07 & \\
\hline Apprenticeship & 0.73 & \\
\hline Master craftsman & 0.12 & \\
\hline University & 0.08 & \\
\hline \multicolumn{3}{|l|}{ Mother's professional education } \\
\hline No professional education & 0.20 & \\
\hline Apprenticeship & 0.76 & \\
\hline Master craftsman & 0.02 & \\
\hline University & 0.02 & \\
\hline Number of siblings: & & \\
\hline Number of families: & 3.2 & \\
\hline
\end{tabular}

Source: German Life History Study, own calculations.

\footnotetext{
7 We use the level of secondary education and not the highest level of completed education to avoid a right censoring problem: younger siblings may not have completed tertiary education at the time of the interview. In addition, secondary educational attainment is commonly used as an indicator of educational attainment in Germany (e.g. Heineck/Riphahn 2009).
} 
education), Realschule (secondary education), and Gymnasium (higher secondary education). After primary schooling, Hauptschule and Realschule take between five and six further years to accomplish while Gymnasium takes further eight or nine years to complete. Realschule and Hauptschule both prepare for an apprenticeship but Realschule rates higher as its curriculum is more demanding. Gymnasium leads to the Abitur and gives access to university education. Using years of schooling as dependent variable is problematic, because it suggests equivalence of all years spent in the school system. Yet, in the German system, one additional year of schooling in Gymnasium is harder to accomplish than one additional year in Realschule. Moreover, one additional year in Realschule is harder to accomplish than one additional year in Hauptschule. So, instead of considering years of schooling, we define four categories as outcomes: no secondary education, lower secondary education, secondary education, and higher secondary education. Among the siblings in our sample, 3 percent have completed no secondary school track, 39 percent have completed lower secondary education, 30 percent have completed secondary education, and 28 percent have completed higher secondary education.

\subsection{Birth order, sibship size and age of mother}

Table 2 shows the distribution of our main explanatory variable birth order. Figure 2 shows that, on a descriptive basis, the relationship between birth order and educational attainment is clearly negative. In the group of the first born, more than 30 percent have a higher secondary education degree whereas in the group of the fifth born or later, the share is only twelve percent. The challenge now is to find out to what extent these patterns can be interpreted as causal.

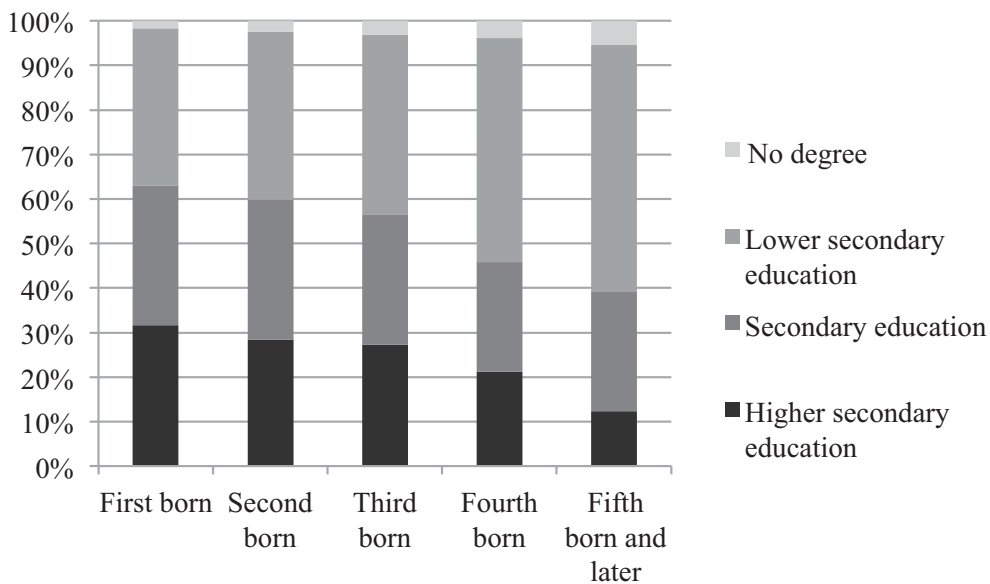

Source: German Life History Study, own calculations.

Figure 2 Relationship between birth order and secondary education 
Table 2 Distributions of birth order and sibship size

\begin{tabular}{ccc}
\hline Birth order & Frequency & Percent \\
\hline 1 & 3,194 & 33.79 \\
2 & 3,135 & 33.16 \\
3 & 1,708 & 18.07 \\
4 & 769 & 8.13 \\
5 & 359 & 3.80 \\
6 & 159 & 1.68 \\
7 & 67 & 0.71 \\
8 & 35 & 0.37 \\
9 & 15 & 0.16 \\
10 & 6 & 0.06 \\
11 & 3 & 0.03 \\
12 & 2 & 0.02 \\
13 & 1 & 0.01 \\
\hline Total & 9,453 & 100 \\
\hline
\end{tabular}

\section{Sibship size}

\begin{tabular}{rrr}
\hline 2 & 2,596 & 27.46 \\
3 & 2,826 & 29.9 \\
4 & 1,731 & 18.31 \\
5 & 1,061 & 11.22 \\
6 & 518 & 5.48 \\
7 & 356 & 3.77 \\
8 & 163 & 1.72 \\
9 & 124 & 1.31 \\
10 & 36 & 0.38 \\
11 & 20 & 0.21 \\
12 & 9 & 0.10 \\
13 & 13 & 0.14 \\
\hline Total & 9,453 & 100 \\
\hline
\end{tabular}

Source: German Life History Study, own calculations.

Note: Differences in the figures for birth order one and birth order two are due to incomplete families in the sample.

To isolate the effect of birth order on educational attainment, our analysis must account for two explanatory factors in particular: sibship size and age of parents. Both are determinants of educational attainment and at the same time show a strong correlation with birth order.

The distribution of the variable sibship size is given in Table $2 .{ }^{8}$ Sibship size is supposed to have a negative impact on educational attainment. According to the resource dilution model (Becker/Lewis 1973; Steelman/Powell 1989), sibship size reduces resources per capita in a family and therefore negatively affects schooling outcomes. As for the relationship between birth order and sibship size, children with lower birth ranks are

8 This variable is based on information of the responding sibling. The variable contains the number of siblings the responding person ever had plus one. 
more likely to have fewer siblings than children with higher birth ranks. In our sample, first born children have on average almost one sibling less than children with birth order two or higher. Because of these correlation patterns, analyses on the relationship between birth order and educational attainment must account for sibship size. It is important to recognize, however, that sibship size is a choice variable of the parents. Parents of large families may differ from parents of small families in observable and unobservable ways. If the unobservable factors also affect children's educational attainment, the estimate of the birth order effect on educational attainment will be biased. In particular, the effect of higher birth orders that only appear in large families may be distorted.

The second important covariate is the age of parents at birth. On the one hand, children with low birth orders are more likely to have younger parents than children born later in the sibling row. For our sample, the average age of mother at birth is around 27. For children with birth order one, it is only around 24 . On the other hand, the age of the parents has itself a positive effect on schooling outcomes (Kalmijm/Kraykaamp 2004). It can be seen as a proxy for the level of parental resources (Kantarevic/Mechoulan 2006). It reflects parents' financial situation and their social capital. Older parents, for instance, are supposed to be financially better off (Mare/Tzeng 1989), calmer, and more experienced in handling children (Fergusson/Woodward 1999). Sociologists also invoke the evolution of the parental role model: older parents are more oriented towards occupational achievement and communicate this attitude to their children (Kalmijm/Kraykaamp 2004). Given the positive impact of parental age on children's educational attainment and its negative correlation with birth order, omitting parental age would bias a negative birth order effect towards zero.

\subsection{Estimation model}

To isolate the effect of birth order on educational attainment, one has to account for underlying family level heterogeneity. In a pooled regression across families, this can be done by including socio-economic proxy variables such as parents' financial and educational background. If information on several siblings of a family is available, a better strategy is to estimate a family fixed effects model and compare children within rather than across families. We apply both strategies.

The baseline estimation technique of this paper is the linear probability model. We choose a linear framework even though schooling outcomes in Germany are non-continuous. The reason for this is that a linear framework offers an easy and established way to control for family fixed effects by estimating a Within or a Least Squares Dummy Variable Model. In a non-linear framework, the inclusion of family fixed effects in the form of indicator variables gives rise to the incidental parameter problem and leads to inconsistent estimates (e.g. Wooldridge 2002). Non-linear models that partial out the family fixed effects, such as Chamberlain's Logit Model, have the disadvantage that they yield no estimates for the actual size of these effects (e.g. Chamberlain 1980). The estimation of predictions and marginal effects must then rely on further assumptions (e.g. Hosmer et al. 2000). ${ }^{9}$

Taking into account the ordered nature of schooling degrees in Germany, we generate two indicator variables that serve as outcomes in our linear probability models. The variable

9 The estimation of predicted values in Chamberlain's Logit Model, for instance, is either conditional on the number of positive outcomes in a group or based on the assumption that the fixed effects are zero. 
hsec assumes the value of one if the individual has higher secondary education and zero otherwise. The variable $\sec$ is assigned the value of one if the individual has at least secondary education (i.e. either higher secondary education or secondary education) and zero otherwise.

In our baseline model, the educational attainment of sibling $i$ from family $j$ is given as:

$$
e d u c_{i j}=\alpha_{0}+\sum_{b=2}^{5} \beta_{b} b_{b i j}+\sum_{s=3}^{5} \gamma_{s}+s i b_{s i j}+\alpha_{1} a g e m_{i j}+\alpha_{2} \operatorname{agef}_{i j}+\alpha_{3} \text { male }_{i j}+\sum_{k} \delta_{k}^{\prime} z+\vartheta_{i}+\varepsilon_{i j}
$$

where educ is either $h s e c$ or $s e c$, depending on whether we model the probability of having higher secondary education ( $h s e c$ ) or having at least secondary education (sec). Our set of explanatory variables consists of birth order (bo), sibship size (sib), age of mother at birth (agem), age of father at birth (agef), and gender (male). We furthermore include socioeconomic proxy variables to capture family level heterogeneity: the vector $z$ comprises parents' secondary and tertiary education, the employment status of the mother during childhood, and cohort indicators in order to capture the effect of educational expansion. To model birth order, we choose a flexible form and create four indicator variables $(b=2$, $3,4,5)$, leaving the first born as the excluded category. Birth ranks of five and higher are grouped together because of the small number of observations in these categories. We similarly proceed with sibship size, and generate three indicator variables $(s=3$, 4,5 ) for the number of children in a family, grouping together sibship sizes of five and higher and leaving children from families with only two children as the excluded category. Age of mother and father are measured in years. The other covariates are all included as indicator variables.

$\vartheta_{i}$ is a family specific error term and $\varepsilon_{i j}$ is an individual specific error term. In a first estimation, we treat $\vartheta_{i}$ as uncorrelated with the regressors and apply a random effects estimator. In a second step, we specify a linear probability model with family fixed effects. In this estimation, all effects that are constant within a family, observed or unobserved, drop out. This model can produce consistent estimates even if $\vartheta_{i}$ is correlated with the regressors. To address the heteroscedasticity problem of linear probability models, we use robust standard errors in all estimations. ${ }^{10}$

\section{Results}

\subsection{Baseline model}

Table 3 provides estimation results of both the random and the fixed effects model using hsec and sec as dependent variables. The tables present estimated coefficients and standard errors. The fixed effects model can only identify the influence of variables that vary across siblings, i.e. birth order, age of mother, male, and the cohort indicators. ${ }^{11}$

${ }^{10}$ Estimating robust standard errors is recommended also when using a random effects or a fixed effects model (see e.g. Wooldridge 2002).

11 As age of mother and age of father vary simultaneously across siblings, it is not possible to identify both effects at the same time. $\alpha_{1}$ can therefore be interpreted as the effect of having older or younger parents relative to the other siblings; $\alpha_{2}$ is not identified. 
Table 3 Results of different linear probability models with hsec and sec as dependent variables

\begin{tabular}{|c|c|c|c|c|}
\hline \multirow[b]{2}{*}{ Variables } & \multicolumn{2}{|c|}{ Dependent variable: $h s e c$} & \multicolumn{2}{|c|}{ Dependent variable: $\sec$} \\
\hline & Random effects & Fixed effects & Random effects & Fixed effects \\
\hline First child & Ref. & Ref. & Ref. & Ref. \\
\hline Second child & $\begin{array}{l}-0.0731^{* * *} \\
(0.0098)\end{array}$ & $\begin{array}{l}-0.0609 * * * \\
(0.0112)\end{array}$ & $\begin{array}{l}-0.0959 * * * \\
(0.0104)\end{array}$ & $\begin{array}{l}-0.0840^{* * *} \\
(0.0123)\end{array}$ \\
\hline Third child & $\begin{array}{l}-0.0832 * * * \\
(0.0135)\end{array}$ & $\begin{array}{l}-0.0602 * * * \\
(0.0166)\end{array}$ & $\begin{array}{l}-0.1207^{* * *} \\
(0.0151)\end{array}$ & $\begin{array}{c}-0.0950^{* * *} \\
(0.0194)\end{array}$ \\
\hline Fourth child & $\begin{array}{l}-0.1273 * * * \\
(0.0186)\end{array}$ & $\begin{array}{l}-0.092^{* * *} \\
(0.0233)\end{array}$ & $\begin{array}{l}-0.1826^{* * *} \\
(0.021)\end{array}$ & $\begin{array}{l}-0.1448 * * * \\
(0.0270)\end{array}$ \\
\hline$\geq$ Fifth child & $\begin{array}{l}-0.1936^{* * *} \\
(0.0210)\end{array}$ & $\begin{array}{l}-0.1449 * * * \\
(0.0279)\end{array}$ & $\begin{array}{l}-0.2167^{* * *} \\
(0.0255)\end{array}$ & $\begin{array}{l}-0.1625^{* * *} \\
(0.0345)\end{array}$ \\
\hline Two siblings & Ref. & Ref. & & \\
\hline Three siblings & $\begin{array}{c}-0.0192 \\
(0.0141)\end{array}$ & $\begin{array}{l}-0.0291 * * \\
(0.0148)\end{array}$ & & \\
\hline Four siblings & $\begin{array}{c}-0.0256 \\
(0.0166)\end{array}$ & $\begin{array}{l}-0.0658 * * * \\
(0.0188)\end{array}$ & & \\
\hline$\geq$ Five siblings & $\begin{array}{l}-0.0678^{* * *} \\
(0.0166)\end{array}$ & $\begin{array}{l}-0.1313^{* * *} \\
(0.0205)\end{array}$ & & \\
\hline Maternal age at birth & $\begin{array}{l}0.0069 * * * \\
(0.0016)\end{array}$ & $\begin{array}{l}0.0066^{* *} \\
(0.0029)\end{array}$ & $\begin{array}{l}0.0039 * * \\
(0.0018)\end{array}$ & $\begin{array}{l}0.0164^{* * *} \\
(0.0037)\end{array}$ \\
\hline Paternal age at birth & $\begin{array}{l}0.0032 * * \\
(0.0014)\end{array}$ & $\begin{array}{l}0.0055^{* * *} \\
(0.0015)\end{array}$ & & \\
\hline Male & $\begin{array}{l}0.0367^{* * *} \\
(0.0078)\end{array}$ & $\begin{array}{l}0.0397^{* * *} \\
(0.0086)\end{array}$ & $\begin{array}{l}-0.0746^{* * *} \\
(0.0085)\end{array}$ & $\begin{array}{l}-0.0731 * * * \\
(0.0094)\end{array}$ \\
\hline $\begin{array}{l}\text { Number of siblings: } \\
\text { Number of families: }\end{array}$ & & & & \\
\hline
\end{tabular}

Source: German Life History Study, own calculations.

Note: The table presents estimated coefficients and robust standard errors in parentheses. The dependent variable hsec (sec) assumes the value of one if the individual has higher secondary education (at least secondary education) and zero otherwise. The standard errors are clustered at family level. ${ }^{* *}{ }^{*}{ }^{*}$, and ${ }^{*}$ indicate statistical significance at the 1, 5, and 10 percent level. All models contain cohort indicators. The random effects models furthermore include controls for parental education and the working status of the mother during childhood.

According to the coefficients of the birth order indicators, being later born significantly decreases both the probability of having higher secondary education ( $h s e c)$ and the probability of having at least secondary education (sec). The birth order effects predicted by the random effects model are stronger. They might, however, be biased by unobserved heterogeneity among families. We test the hypothesis that the coefficient vectors of the random and the fixed effects models are identical by a heteroscedasticity robust version of the Hausman test (Wooldridge 2002). ${ }^{12}$ The Null hypothesis is clearly rejected both in the case of $h \sec (p=0.001)$ and $\sec (p=0.000)$. This indicates that the results of the random effects models are indeed affected by unobserved heterogeneity. As a consequence, from now on, we focus on the fixed effects models.

${ }^{12}$ In Stata, this test is implemented by the user-written command xtoverid (Schaffer/Stillman 2010). 
According to the linear fixed effects model, being the second born child in a family reduces the probability of completing higher secondary education (or at least secondary education) by around 6 (8.4) percentage points compared to the first born child of the family. The disadvantage grows with rising birth order. The strongest effect is found for children born fifth or later. They have a 14 (16) percentage points lower probability of achieving higher secondary education (at least secondary education) than the first born child of the respective family.

\subsection{Heterogeneities}

\subsubsection{Gender}

This section investigates whether birth order effects differ by gender. Given the large number of theories to explain birth order effects (c.f. section 2) one could also formulate a large number of hypotheses on why birth order effects should differ by gender. For brevity, however, this section focuses on economic explanatory approaches.

Human capital theory explains the birth order effects by a decline in parental resources with rising birth order. Here, gender differences would be the result of either (i) a genderspecific differential parental treatment of later born children or (ii) a gender-specific need for parental resources. As for the first explanation (i), Price (2008) shows that the decline in parent-child quality time with birth order cumulated over childhood is higher for girls than for boys. This is evidence to suggest that later born girls might get fewer resources with respect to the first born child than later born boys. Thus, if the first explanation holds, we would expect the birth order effects to be stronger for girls. With regard to the second explanation (ii), useful insights can be gained by consulting the literature on missing parents and child development. Similar to children who have lost one or both parents, later born children might be confronted with a lack of parental resources in their critical developing years. According to results from the missing parent literature boys suffer more severely from the absence of one parent than girls. ${ }^{13}$ This indicates that the educational attainment of boys is more sensitive to parental input than that of girls. If this explanation holds, we would expect the birth order effects to be stronger for boys. Earlier studies on birth order effects found stronger effects for girls (Black et al. 2005; Booth/Kee 2009) or did not mention any significant gender differences (Kantarevic/Mechoulan 2006; de Haan 2010). However, these studies did not use a family fixed effects regression when testing for heterogeneous birth order effects. In a cross family regression there might be other gender specific effects interfering.

We completely interact the linear fixed effects models with a gender indicator (Table 4). The coefficients of the interaction terms between birth order and male are all negative and jointly significant ( $h s e c: p=0.06$, sec: $p=0.01$ ). Except for the interaction term between birth order three and male in the model with hsec as dependent variable they are also significant at the individual level $(p \leq 0.1)$. The coefficients suggest that the disadvantage of coming later in the sibling row is approximately twice as strong for

\footnotetext{
${ }^{13}$ See for example Krein and Beller (1988). They find that the consequences of living in a single-parent household crucially depend on the length of time a child lived with only one parent. These findings are consistent with the economic parental resources approach. Furthermore, the time effects are stronger and only significant for boys.
} 
boys. ${ }^{14}$ For example, for a girl, being only the second born child in a family reduces her probability of completing higher secondary education by around 4 percentage points. For a boy, this disadvantage amounts to around 8 percentage points. The result of stronger birth order effects for boys is consistent with explanation (i) implying that the educational attainment of boys is more sensitive to parental input than that of girls.

Table 4 Results of family fixed effects linear probability models with hsec and sec as dependent variables: allowing for gender differences in the birth order effects

\begin{tabular}{|c|c|c|}
\hline Variables & Dependent variable: $h s e c$ & Dependent variable: sec \\
\hline First child & Ref. & Ref. \\
\hline Second child & $\begin{array}{l}-0.0388^{* *} \\
(0.0154)\end{array}$ & $\begin{array}{l}-0.0591 * * * \\
(0.0169)\end{array}$ \\
\hline Third child & $\begin{array}{c}-0.0393^{*} \\
(0.0211)\end{array}$ & $\begin{array}{l}-0.0692^{* * *} \\
(0.0238)\end{array}$ \\
\hline Fourth child & $\begin{array}{c}-0.0471^{*} \\
(0.0285)\end{array}$ & $\begin{array}{l}-0.0786^{* *} \\
(0.0333)\end{array}$ \\
\hline$\geq$ Fifth child & $\begin{array}{l}-0.1035^{* * *} \\
(0.0331)\end{array}$ & $\begin{array}{l}-0.1227^{* * *} \\
(0.0393)\end{array}$ \\
\hline Maternal age at birth & $\begin{array}{l}0.005 \\
(0.0031)\end{array}$ & $\begin{array}{l}0.0169 * * * \\
(0.0038)\end{array}$ \\
\hline Male & $\begin{array}{c}-0.0051 \\
(0.0473)\end{array}$ & $\begin{array}{c}-0.0056 \\
(0.0548)\end{array}$ \\
\hline Second $*$ Male & $\begin{array}{c}-0.0420^{*} \\
(0.0221)\end{array}$ & $\begin{array}{l}-0.0477^{* *} \\
(0.0237)\end{array}$ \\
\hline Third * Male & $\begin{array}{c}-0.0395 \\
(0.0266)\end{array}$ & $\begin{array}{c}-0.0496^{*} \\
(0.0291)\end{array}$ \\
\hline Fourth * Male & $\begin{array}{l}-0.0838^{* * *} \\
(0.0321)\end{array}$ & $\begin{array}{l}-0.1243^{* * *} \\
(0.0361)\end{array}$ \\
\hline Fifth * Male & $\begin{array}{l}-0.0787^{* *} \\
(0.0318)\end{array}$ & $\begin{array}{l}-0.0784^{* *} \\
(0.0400)\end{array}$ \\
\hline Maternal age * Male & $\begin{array}{l}0.0029 \\
(0.0019)\end{array}$ & $\begin{array}{l}-0.0008 \\
(0.0021)\end{array}$ \\
\hline Number of siblings: & \multicolumn{2}{|c|}{9,453} \\
\hline Number of families: & \multicolumn{2}{|c|}{3,282} \\
\hline
\end{tabular}

\footnotetext{
${ }^{14}$ In terms of gender heterogeneities, we also examined possible effects of a sex-specific birth order, i.e., we checked whether being born the first male or first female child has a separate impact on schooling. Such an influence is best explained by a diminishing utility in parenting from the first to the second child, which is less pronounced if the second child is of different sex. Yet, we find no significant effect of the sex-specific birth rank.
} 


\subsubsection{Family size}

In this section, we test whether birth order effects differ by sibship size. Such heterogeneities appear if the relative disadvantage of a given birth order depends on the number of younger siblings in the family. Most of the theories cited in section 2 would predict weaker effects in large families.

First, according to the optimal stopping theory, parents base their fertility decision on their experience with previous children. Thus, for a child with a given birth order, having younger siblings indicates a good parent-child relationship in early childhood and a sufficient supply of parental resources. A child's disadvantage of not being first born should therefore be the smaller, the more younger siblings there are in the family. The negative effect of a given birth order should be the weaker, the larger the sibship size.

Second, following Zajonc and Markus (1979), children profit from tutoring their younger siblings. In a two-child-family, the first child can teach the second child and therefore has an advantage over the second child. In a three-child-family, the second child can compensate some of this disadvantage by teaching the third child of the family. Again, this mechanism implies weaker effects in large families.

As for previous empirical studies, the findings on a possible interaction of birth order and sibship size are mixed. Black et al. (2005) find that birth order effects decrease with family size whereas Kantarevic and Mechoulan (2006) and de Haan (2010) obtain the converse result. However, these studies did not test whether the interaction effects are significant.

We completely interact the linear family fixed effects model with the variable sibship size. The results are given in Table 5. As for the probability of having higher secondary education ( $h s e c$ ) the disadvantage of being later born declines significantly with sibship size. This result is in line both with the optimal stopping theory and the idea that children profit from tutoring younger siblings. In contrast, there are no significant interaction effects between birth order and sibship size in the model that uses sec as dependent variable.

\subsubsection{Further sibling configuration components}

Besides birth order and sibship size, there are other components of sibling configuration that determine a child's relative position in a family and therefore might affect educational attainment (see Steelman et al. 2002 for an overview). In this section, we add age-spacing, also known as sibship density, and sex composition of the siblings to our model. Following de Haan (2010), we also test whether there are interaction effects between birth order and other components of sibling configuration, because they jointly determine the relative position of a child within a family.

According to the resource dilution model, being closely spaced with the other siblings should constitute a disadvantage for a child: workload, stress and financial burden of parenting are more intense, and there are fewer resources available for each child than in widely spaced sibships (Steelman/Powell 1993). To describe the spacing, we create two variables: at the family level, we calculate the distance between the first child and the last child. At the individual level, we generate a variable indicating for each child the average time lag to its next older and next younger sibling. ${ }^{15}$ ${ }^{15}$ If it is the oldest child, we use the distance to its next youngest sibling, if it is the youngest child
we use the distance to its next older sibling. 
Table 5 Results of family fixed effects linear probability models with hsec and sec as dependent variables: allowing for family size differences in the birth order effects

\begin{tabular}{|c|c|c|}
\hline Variables & Dependent variable: $h s e c$ & Dependent variable: sec \\
\hline First child & Ref. & Ref. \\
\hline Second child & $\begin{array}{l}-0.1475^{* * *} \\
(0.0274)\end{array}$ & $\begin{array}{l}-0.0988^{* * *} \\
(0.0302)\end{array}$ \\
\hline Third child & $\begin{array}{l}-0.1834^{* * *} \\
(0.0412)\end{array}$ & $\begin{array}{c}-0.0963^{*} \\
(0.0506)\end{array}$ \\
\hline Fourth child & $\begin{array}{l}-0.3083^{* * *} \\
(0.0702)\end{array}$ & $\begin{array}{l}-0.2348^{* * *} \\
(0.0757)\end{array}$ \\
\hline$\geq$ Fifth child & $\begin{array}{l}-0.4061 * * * \\
(0.0766)\end{array}$ & $\begin{array}{c}-0.1951 * * \\
(0.0946)\end{array}$ \\
\hline Maternal age at birth & $\begin{array}{l}0.0235^{* * *} \\
(0.0051)\end{array}$ & $\begin{array}{l}0.0177^{* * *} \\
(0.0063)\end{array}$ \\
\hline Male & $\begin{array}{l}0.0403 * * \\
(0.0198)\end{array}$ & $\begin{array}{l}-0.0740^{* * *} \\
(0.0217)\end{array}$ \\
\hline Second * Sibship size & $\begin{array}{l}0.0211^{* * *} \\
(0.0065)\end{array}$ & $\begin{array}{c}0.0039 \\
(0.0076)\end{array}$ \\
\hline Third * Sibship size & $\begin{array}{l}0.0272 * * * \\
(0.008)\end{array}$ & $\begin{array}{c}-0.0003 \\
(0.0103)\end{array}$ \\
\hline Fourth * Sibship size & $\begin{array}{l}0.0463^{* * *} \\
(0.0127)\end{array}$ & $\begin{array}{c}0.0176 \\
(0.0140)\end{array}$ \\
\hline Fifth * Sibship size & $\begin{array}{l}0.0558^{* * *} \\
(0.013)\end{array}$ & $\begin{array}{c}0.0061 \\
(0.0154)\end{array}$ \\
\hline Maternal age * Sibship size & $\begin{array}{c}-0.0038 \\
(0.0010)\end{array}$ & $\begin{array}{c}-0.0002 \\
(0.0013)\end{array}$ \\
\hline Male * Sibship size & $\begin{array}{l}0.0004^{* * *} \\
(0.0039)\end{array}$ & $\begin{array}{c}-0.0002 \\
(0.0049)\end{array}$ \\
\hline $\begin{array}{l}\text { Number of siblings: } \\
\text { Number of families: }\end{array}$ & \multicolumn{2}{|c|}{$\begin{array}{l}9,453 \\
3,282\end{array}$} \\
\hline
\end{tabular}

Note: See Table 4.

The most general description of sibling sex composition is the percentage of boys and girls in a family. There are various theories that predict opposing effects (see Bauer/Gang 2001 for an overview). We shortly outline two approaches, which both predict a negative effect of having brothers. The first theory follows Becker and Tomes (1976) and assumes that parents invest a greater share of resources in the children with the highest returns. Because of the prevailing gender wage gap in favor of men, parents might tend to invest more heavily in male children so that boys get a greater share of resources than girls. That is, having a sister instead of a brother is an advantage, as more resources remain. Another theory is based on gender-specific traits a child takes on, depending on sibling sex composition (Butcher/Case 1994). If, e.g., feminine traits are favorable in the school system, children who grow up with female siblings will have an advantage over children with no female siblings as they will be able to acquire more feminine traits. To test the influence of sex composition, we generate for each child a variable that indicates the percentage of brothers among its siblings. 
We include the new variables in the random effects and the fixed effects model (results not presented). ${ }^{16}$ Just as in earlier studies (e.g., Bauer/Gang 2001; Blaess 2005; de Haan 2010), the additional sibling configuration variables are not statistically significant and their inclusion does not change the other coefficients. In order to test whether there are interaction effects between birth order and other components of sibling configuration, we completely interact the baseline linear fixed effects model with the variables for sex composition and child spacing, respectively. The interaction terms between birth order and sex composition are neither individually nor jointly significant. As for the interaction terms between birth order and child spacing they are positive and significant for birth orders two and three but not jointly significant (results not presented). Sibling configuration aspects other than birth order and sibship size apparently play no role in explaining educational success in the German school systems.

\section{Robustness check: stable families only}

A common objection to the empirical findings on birth order effects is that the observed patterns are caused by family problems (e.g. divorce or death of a parent) which later born children are more likely to experience during their developing years than their older siblings. To address this point, we repeat parts of our analysis with the subsample of families for which we can be certain that the biological parents of the respondent never split up. This sample contains only 4,811 siblings from 1,719 families with at least two children. The results for the baseline linear fixed effects model are shown in Table 6 . Although the sample size is now halved, the coefficients of the birth order indicators are still statistically significant and negative, and very close to those for the entire sample (cf. Table 3).

\section{Conclusion}

This study investigates the effect of sibling birth order on secondary education for West German siblings born between 1946 and 1977. Based on data provided by the German Life History Study we estimate several linear probability models with family fixed effects. Similar to previous studies from Norway, the U.K. and the U.S, we find highly significant disadvantages for later born children: Second born children have a 6 percentage points lower probability of attaining higher secondary education than the oldest child of a family. For children with birth order five or higher this disadvantage is even 14 percentage points. Testing for heterogeneities, we find that the effects are stronger for boys. This is consistent with findings from the missing parents literature where a lack of parental resources is also more harmful for the development of boys. Furthermore, we find that the disadvantage of a given birth order is less pronounced if there are further younger siblings in the family. This could indicate a beneficial effect of teaching and taking care of younger siblings or suggest that children with younger siblings are a "positive selection" as parents decided to have further children.

The finding that later born children are doing systematically worse in the German school system has interesting implications for the discussion on equal opportunities in Germany. Using correlations between siblings as an indicator Schnitzlein (2014) finds that between

${ }_{16}$ The variable for spacing at the family level could only be included in the ordered logit and the random effects model as it does not vary across siblings. 
Table 6 Results of family fixed effects linear probability models with hsec and sec as dependent variables for families with permanently married parents

\begin{tabular}{|c|c|c|}
\hline Variables & Dependent variable: $h s e c$ & Dependent variable: sec \\
\hline First child & Ref. & Ref. \\
\hline Second child & $\begin{array}{l}-0.0568 * * * \\
(0.0165)\end{array}$ & $\begin{array}{l}-0.0649 * * * \\
(0.0180)\end{array}$ \\
\hline Third child & $\begin{array}{c}-0.0473^{*} \\
(0.0249)\end{array}$ & $\begin{array}{l}-0.0675^{* *} \\
(0.0298)\end{array}$ \\
\hline Fourth child & $\begin{array}{c}-0.0634^{*} \\
(0.0353)\end{array}$ & $\begin{array}{l}-0.1063^{* *} \\
(0.0419)\end{array}$ \\
\hline$\geq$ Fifth child & $\begin{array}{l}-0.1302^{* * *} \\
(0.0419)\end{array}$ & $\begin{array}{l}-0.1329^{* *} \\
(0.0536)\end{array}$ \\
\hline Maternal age at birth & $\begin{array}{c}0.0051 \\
(0.0033)\end{array}$ & $\begin{array}{l}0.0178^{* * *} \\
(0.0056)\end{array}$ \\
\hline Male & $\begin{array}{l}0.0401^{* * *} \\
(0.0131)\end{array}$ & $\begin{array}{l}-0.1015^{* * *} \\
(0.0139)\end{array}$ \\
\hline $\begin{array}{l}\text { Number of siblings: } \\
\text { Number of families: }\end{array}$ & \multicolumn{2}{|c|}{$\begin{array}{l}4,811 \\
1,719\end{array}$} \\
\hline
\end{tabular}

Note: See Table 4.

39 and 43 percent of the variation in permanent earnings in Germany can be attributed to family background. Intergenerational mobility in Germany is thereby found to be substantially lower than in Denmark and comparable to that in the U.S. However, these sibling comparisons are not conditioned on birth order. Yet, siblings from the same family necessarily have different birth ranks and our study has shown that in Germany different birth ranks imply different educational success. This could lead to an underestimation of the total impact of family background in Germany and other countries and distort international comparisons. It would be a useful robustness check to test whether these results are sensitive to the inclusion of birth order.

\section{References}

Bauer, T., I. Gang (2001), Sibling Rivalry in Educational Attainment: The German Case. Labour 15(2): 237-255.

Becker, G. (1981), A Treatise on the Family. Cambridge: Harvard University Press.

Becker, G. (1996), Accounting for Tastes. Cambridge: Harvard University Press.

Becker, G., H. Lewis (1973), On the Interaction between the Quantity and Quality of Children. Journal of Political Economy 81(2): S279-S288.

Becker, G., N. Tomes (1976), Child Endowments and the Quantity and Quality of Children. Journal of Political Economy 84(4): S143-S162.

Behrman, J., P. Taubman (1986), Birth Order, Schooling, and Earnings. Journal of Labor Economics 4(3): 121-145.

Björklund, A., L. Lindahl, M. Lindquist (2010), What More Than Parental Income, Education and Occupation? An Exploration of What Swedish Siblings Get from Their Parents. The B.E. Journal of Economic Analysis and Policy 10 (1) (Contributions), Article 102.

Black, E., P. Devereux, K. Salvanes (2005), The More the Merrier? The Effect of Family Size and Birth Order on Children's Education. The Quarterly Journal of Economics 120(2): 669-700. 
Blaess, V. (2005), Siblings and Educational Attainment in West Germany. Discussion Paper Universität Erfurt, No. 2005,001E.

Booth, A., H. Kee (2009), The Effect of Family Size and Birth Order on Educational Attainment. Journal of Population Economics 22(2): 367-397.

Borghans, L., A. Duckworth, J. Heckman, B. Weel (2008), The Economics and Psychology of Personality Traits. IZA Discussion Paper, No. 3333, Bonn.

Brückner, E., K. Mayer (1998), Collecting Life History Data: Experiences on the German Life History Study. Pp. 152-181 in: J. Giele, G. Elder, Jr. (eds.), Methods of Life Course Research: Qualitative and Quantitative Approaches. London: Sage Publications Inc.

Butcher, K., A. Case (1994), The Effect of Sibling Sex Composition on Women's Education and Earnings. The Quarterly Journal of Economics 109(3): 531-563.

Chamberlain, G. (1980), Analysis of Covariance with Qualitative Data. Review of Economic Studies 47(1): 225-238.

Conley, D., R. Glauber (2008), All in the Family? Family Composition, Resources, and Sibling Similarity in Socio-Economic Status. Research in Social Stratification and Mobility 26(4): 297-306.

Currie, J., M. Stabile (2006), Child Mental Health and Human Capital Accumulation: The Case of ADHD. Journal of Health Economics 25(6): 1094-1118.

de Haan, M. (2010), Birth Order, Family Size and Educational Attainment. Economics of Education Review 29(4): 576-588.

Eschelbach, M. (2009), Crown Princes and Benjamins: Birth order and Educational Attainment in East and West Germany. BGPE Discussion Paper, No. 85.

Fergusson, D., L. Woodward (1999), Maternal Age and Educational and Psychosocial Outcomes in Early Adulthood. Journal of Child Psychology and Psychiatry and Allied Disciplines 40(3): 479-489.

Fletcher, J., B. Wolfe (2008), Child Mental Health and Human Capital Accumulation: The Case of ADHD Revisited. Journal of Health Economics 27(5): 794-800.

Hauser, R., R. Wong (1989), Sibling resemblance and intersibling effects in educational attainment. Sociology of Education 62(3): 149-171.

Healey, M., B. Ellis (2007), Birth Order, Conscientiousness, and Openness to Experience: Tests of the Family-Niche Model of Personality Using a Within-Family Methodology. Evolution and Human Behavior 28(1): 55-59.

Heckman, J. (2008), Schools, Skills, and Synapses. Economic Inquiry 46(3): 289-324.

Heckman, J., J. Stixrud, S. Urzua (2006), The Effects of Cognitive and Noncognitive Abilities on Labor Market Outcomes and Social Behavior. Journal of Labor Economics 24(3): 411-482.

Heineck, G., R. Riphahn (2009), Intergenerational Transmission of Educational Attainment in Germany - The Last Five Decades. Jahrbücher für Nationalökonomie und Statistik 229(1): 36-60.

Herrera, N., R. Zajonc, G. Wieczorkowska, B. Cichomski (2003), Beliefs about Birth Rank and Their Reflections in Reality. Journal of Personality and Social Psychology 85(1): 142-150.

Hertwig, R., J. Davis, F. Sulloway (2002), Parental Investment: How an Equity motive Can Produce Inequality. Psychological Bulletin 128(5): 728-745.

Hosmer, D., S. Lemeshow, R. Sturdivant (2000), Applied Logistic Regression. New York: Wiley.

Kalmijn, M., G. Kraaykamp (2004), Late or Later? A Sibling Analysis of the Effect of Maternal Age on Children's Schooling. Social Science Research 34(3): 634-650.

Kantarevic, J., S. Mechoulan (2006), Birth Order, Educational Attainment, and Earnings. An Investigation Using the PSID. Journal of Human Resources 41(4): 755-777.

Krein, S., A. Beller (1988), Educational Attainment of Children from Single-Parent Families: Differences by Exposure, Gender, and Race. Demography 25(2): 221-234.

Mare, R., M. Tzeng (1989), Fathers' Ages and the Social Stratification of Sons. American Journal of Sociology 95(1): 108-131.

Mazumder, B. (2008), Sibling Similarities and Economic Inequality in the US. Journal of Population Economics 21(3): 685-701.

Paulhus, D., P. Trapnell, D. Chen (1999), Birth Order and Personality within Families. Psychological Science 10: 482-488. 
Price, J. (2008), Parent-Child Quality Time. Does Birth Order Matter? Journal of Human Resources 43(1): 240-265.

Schaffer, M., S. Stillman (2010), xtoverid: Stata module to calculate tests of overidentifying restrictions after xtreg, xtivreg, xtivreg2 and xthtaylor, http://ideas.repec.org/c/boc/bocode/ s456779.html.

Schnitzlein, D. (2014), How Important Is the Family? Evidence from Sibling Correlations in Permanent Earnings in the USA, Germany, and Denmark. Journal of Population Economics 27(1): 69-89.

Shonkoff, J., D. Phillips (2000), From Neurons to Neighborhoods: The Science of Early Child Development, Washington, DC: National Academy Press.

Sieben, I., J. Huinink, P. de Graaf (2001), Family background and sibling resemblance in educational attainment: Trends in the former FRG, the former GDR and the Netherlands. European Sociological Review 17(4): 401-430.

Solon, G., M. Corcoran, R. Gordon, D. Laren (1991), A Longitudinal Analysis of Sibling Correlations in Economic Status. Journal of Human Resources 26(3): 509-534.

Steelman, L., B. Powell (1989), Acquiring Capital for College: The Constraints of Family Configuration. American Sociological Review 54(5): 844-855.

Steelman, L., B. Powell (1993), The Educational Benefits of Being Spaced Out: Sibship Density and Educational Progress. American Sociological Review 58(3): 367-381.

Steelman, L., B. Powell, R. Werum, S. Carter (2002), Reconsidering the Effects of Sibling Configuration: Recent Advances and Challenges, Annual Review of Sociology 28 (1): 243-269.

Sulloway, F. (1996), Born to Rebel: Birth Order, Family Dynamics, and Revolutionary Genius. New York: Pantheon.

Sulloway, F. (2001), Birth Order, Sibling Competition, and Human Behavior. Pp. 39-83 in: H. Holcomb (ed.), Conceptual Challenges in Evolutionary Psychology: Innovative Research Strategies. Dordrecht and Boston: Kluwer Academic Publishers.

Sulloway, F. (2007a), Birth Order. Pp. 162-182 in: C. Salmon, T. Shackelford (eds.), Evolutionary Family Psychology. Oxford and New York: Oxford University Press.

Sulloway, F. (2007b), Birth Order and Sibling Competition. Pp. 297-311 in: R. Dunbar, L. Barrett (eds.), The Oxford Handbook of Evolutionary Psychology. Oxford: Oxford University Press.

Wössmann, L. (2004), How Equal Are Educational Opportunities? Family Background and Student Achievement in Europe and the United States. IZA Discussion Papers 1284, Institute for the Study of Labor (IZA).

Wooldridge, J. (2002), Econometric Analysis of Cross Section and Panel Data. London: MIT Press.

Zajonc, R. (1976), Family Configuration and Intelligence. Science 192(4236): 227-236.

Zajonc, R., G. Markus (1979), The Birth Order Puzzle. Journal of Personality and Social Psychology 37(8): 1325-1341.

Dr. Martina Eschelbach, Deutsche Bundesbank, Wilhelm-Epstein-Straße 14, 60431 Frankfurt a.M., Germany, and University of Erlangen-Nuremberg, Lange Gasse 20, 90403 Nuremberg, Germany.

martina.eschelbach@bundesbank.de 